\title{
Revisitando os Direitos Reais a Partir de sua Interface com o Direito Obrigacional: a importância da relatividade entre os planos real e obrigacional nas relações privadas
}

\author{
Carlos Eduardo Pianovski Ruzyk ${ }^{1}$ \\ Felipe Frank ${ }^{2}$
}

\begin{abstract}
Resumo: A partir da concepção de que a relação obrigacional é um processo inserido num complexo de relações econômicas desenvolvidas através das mais diferentes combinações e possibilidades fáticas e contratuais, nem sempre tuteladas adequadamente pelo Direito (ex: compromisso de compra e venda sem registro em cartório, contrato de gaveta etc.), verificar-se-á que a relativização da divisão entre os planos real e obrigacional é essencial à compreensão jurídica da ressignificação dos conceitos de posse e propriedade a partir da função social, que atribui autonomia à posse e transforma a propriedade em contributo, viabilizando a liberdade material da pessoa humana e a concretização dos direitos fundamentais constitucionalmente assegurados, em especial o direito à moradia.
\end{abstract}

Palavras-chave: Relativização entre Direitos Reais e Obrigacionais. Elementos constituintes da Propriedade. Autonomia da Posse. Teoria Crítica do Direito Civil.

\begin{abstract}
Adopting the conception that the obligation is a process entered into a complex structure of economic relationships, developed through several combinations of factual and contractual possibilities, which may not be protected by Law (e.g. promissory contract of purchase and sale without register in notary's office), we will figure out that the relativization between Property Law and Law of Obligations is something essential to the legal comprehension about social function of property and of possession in Brazilian Law. This social function gives autonomy to the possession and deals the property such as contribute, enabling both material freedom of human being and material realization of fundamental rights, specially the housing rights.
\end{abstract}

Keywords: Relativization between Property Law and Law of Obligations. Property's elements. Possession's autonomy. Critical Theory of Civil Law.

\footnotetext{
${ }^{1}$ Mestre e Doutor em Direito pela Universidade Federal do Paraná (UFPR). Professor de Direito Civil na UFPR (Graduação e Pós-Graduação) e na PUC/PR. Advogado. E-mail: carlospianovski@ hotmail.com.

${ }^{2}$ Acadêmico do $5^{\circ}$ ano da Faculdade de Direito da UFPR. Bolsista do Programa de Iniciação Científica da UFPR 2010/2012. Pesquisador do Núcleo de Estudos em Direito Civil-Constitucional Virada de Copérnico. Estagiário de pesquisa vinculado ao Prof. Dr. Luiz Edson Fachin.E-mail: felipefrank89@ gmail.com.
}

Recebido em: 31/03/2011.

Revisado em: 26/04/2011.

Aprovado em: 10/09/2011. 


\section{Introdução}

Há muito a estrutura estática que separava o plano obrigacional do real foi questionada pela doutrina nacional. Clóvis do Couto e Silva, em 1964, além de defender a inexistência de uma relação obrigacional estática, composta essencialmente por uma parte credora e por outra devedora, ofereceu subsídios para afirmar a relatividade da separação entre os planos obrigacional e real.

Questionada à época, a separação absoluta dos planos ainda não foi abjurada por toda a doutrina. Carecendo de maiores explicações nos manuais civilistas, os direitos reais costumam ser analisados sem tratamento interdisciplinar envolvendo o enfoque contratual.

A partir da concepção de que a relação obrigacional é um processo inserido num complexo de relações econômicas desenvolvidas dentro do mercado por meio das mais diferentes combinações e possibilidades fáticas e contratuais, as quais, por sua vez, nem sempre encontram tutela adequada pelo Direito, analisar-se-á a eficácia e o respectivo tratamento jurídico de alguns pontos controvertidos que envolvem obrigações diretamente vinculadas a direitos reais, como o chamado contrato de gaveta.

Essa análise parte da delimitação dos conceitos tradicionais criados para orientar a tutela dos direitos envolvidos nestas relações e busca, a partir de uma análise crítica, encontrar melhores saídas doutrinárias para a efetivação dos direitos daqueles, muitas vezes, que estão à margem do sistema jurídico posto, assegurando, a estes, a implementação de sua $l i$ berdade em sentido material.

A compreensão da análise a que se propõe este artigo, que preconiza um repensar da separação radical entre as relações obrigacionais e os direitos reais - inserindo-os na categoria mais ampla das situações subjetivas patrimoniais, funcionalizadas às situações existenciais - pressupõe, como primeiro passo, o reexame de alguns conceitos tradicionais no Direito Civil, para, em seguida, oferecer exemplos sobre como poderia ser possível não apenas revelar a relativização da separação, mas, também, direcionar tal mitigação a um telos funcional centrado na proteção de interesses existenciais. É o que se fará a seguir. 


\section{1 (Re)definição dos Conceitos Tradicionais}

\subsection{Obrigação}

Obrigação, segundo Silvio Rodrigues, é

[...] o vínculo de direito pelo qual alguém (sujeito passivo) se propõe a dar, fazer ou não fazer qualquer coisa (objeto), em favor de outrem (sujeito ativo)." (RODRIGUES, 2002, p. 3).

Esse vínculo de direito é definido por Marcos Bernardes de Mello como relação jurídica, a qual também pode ser chamada de situação jurídica multilateral, uma vez que:

[...] há relação jurídica (= situação jurídica multilateral) quando a situação jurídica exige para existir, em caráter de essencialidade, que haja intersubjetividade jurídica, isto é, relacionamento ao menos entre dois sujeitos de direito, que implique correspectividade de direito-dever e das demais categorias eficaciais que constituem o seu conteúdo típico (MELLO, 2008, p. 182).

Esse conceito pandectista de relação jurídica, entretanto, deixa de lado algumas situações com relevância jurídica, como, por exemplo, os direitos reais, nos quais não haveria intersubjetividade propriamente dita, já que a ligação seria entre um sujeito e uma coisa. Não faltaram, todavia, argumentos que rebatessem essa crítica, alegando que também pode haver uma relação jurídica entre uma pessoa e uma coisa. Isso sem falar na teoria personalista - que vislumbra na relação jurídica de Direito Real a existência de um ente passivo universal (a coletividade) - e na teoria mista, que agrega ambas; todavia, essas diferentes teorias serão explicadas de melhor forma quando o conceito de propriedade for abordado.

Segundo Antunes Varela (1997), o termo obrigação é polissêmico, podendo significar: 1) um dever jurídico, ou seja, algo que foi imposto pelo direito e deve ser observado pelas pessoas sob pena de sanção; 2) um estado de sujeição, no qual uma parte fica adstrita à outra através de um direito potestativo (e.g.: mandato); 3) um ônus jurídico, o qual se exige 
apenas da parte interessada sob pena de não produzir os efeitos jurídicos visados (e.g.: inscrever o imóvel no registro de imóveis após a compra e venda); 4) direitos-deveres ou poderes funcionais, os quais estão ligados a características muito próprias da função da qual derivam (e.g.: deveres do cônjuge, poder parental, tutela, curatela etc.); 5) por fim, pode ser entendido na sua acepção técnica, consubstanciando-se numa relação jurídica obrigacional.

A Obrigação, portanto, deve ser compreendida em seu conceito estrito, técnico, o qual, entretanto, não se encerra no conceito trazido pela doutrina clássica, já que ela abrange a relação no seu conjunto, e não apenas a existência de um credor num polo e de um devedor noutro. Ela é uma via de duas mãos, e não uma via de mão única; é, segundo Karl Larenz e Clóvis do Couto e Silva, simultaneamente uma relação de crédito e débito para ambas as partes, que guardam direitos e deveres recíprocos. E maior ainda será a complexidade desta obrigação na medida em que as relações econômicas nela consubstanciadas envolverem formas atípicas de acordo de vontades, bem como quando houver a transmissão de bens através da coligação de contratos estruturalmente diferentes e funcionalmente correlatos, gerando as chamadas redes contratuais.

\subsection{Contrato}

O contrato figura dentro do plano obrigacional como uma de suas principais fontes, senão como a principal. Para Orlando Gomes (2009, p. 4-5)

[...] contrato é uma espécie de negócio jurídico que se distingue, na formação, por exigir a presença pelo menos de duas partes [...]. [Os contratos são] instrumentos jurídicos para a constituição, transmissão e extinção de direitos na área econômica.

Destaque-se que os contratos são espécie do gênero negócio jurídico, diferenciando-se pelo fato de que neles as partes têm a "[...] liberdade de estruturar o conteúdo de eficácia da relação jurídica resultante." (MELLO, 2008, p. 68). 
Entretanto, segundo Rodrigo Xavier Leonardo (LEONARDO, 2005), podem os contratos não apenas transferir direitos na área econômica, mas também criar direitos, como ocorre, por exemplo, com o contrato de leasing - no qual o valor de uso conferido pelo contrato é maior do que o valor residual de garantia - e de cessão de créditos frente à transmissão de bens - no qual o crédito torna-se mercadoria, potencializando as possibilidades de transmissão dos bens.

\subsection{Direito Real de Propriedade}

O Direito Real, segundo Orlando Gomes (1999, p. 7)

[...] regula o poder dos homens sobre os bens e os modos de sua utilização econômica [...]. O Direito das Coisas se resume a definir o poder do homem, no aspecto jurídico, sobre a natureza física [...] e em regular a aquisição, o exercício, a conservação, a reivindicação e a perda daquele poder, à luz dos princípios consagrados nas leis positivas.

A distinção, para o referido autor, entre Direitos Reais e Obrigacionais depende da teoria a ser adotada (realista ou personalista):

Os adeptos da teoria realista caracterizam o direito real como o poder imediato da pessoa sobre a coisa, que se exerce erga omnes. O direito pessoal, ao contrário, opõe-se unicamente a uma pessoa, de quem se exige determinado comportamento (GOMES, 1999, p. 11). Contra essa concepção levantaram-se duas objeções principais: a primeira, a de que não pode haver relação jurídica senão entre pessoas; a segunda, a de que a oponibilidade a terceiros não é peculiaridade dos direitos reais, mas característica de todos os direitos absolutos. Impressionados com a sustentada inexistência de uma relação jurídica entre pessoa e coisa, muitos autores adotaram a teoria personalista, segundo a qual os direitos reais também são relações jurídicas entre pessoas, como os direitos pessoais. A diferença está no sujeito passivo. Enquanto no direito pessoal, esse sujeito passivo - o devedor - é pessoa certa e determinada, no direito real, seria indeterminada, havendo, nesse caso, uma obrigação positiva 
universal, a de respeitar o direito - obrigação se concretiza toda vez que alguém o viola (GOMES, 1999, p. 12).

Frente à imprecisão técnica de ambas as teorias, segundo Orlando Gomes, a melhor forma de distinguir direitos reais dos obrigacionais é o modo de seu exercício. Afinal,

[...] a característica do direito real será sempre o fato de se exercer diretamente, sem interposição de quem quer que seja, enquanto o direito pessoal supõe necessariamente a intervenção de outro sujeito de direito. Assim, o proprietário, titular do máximo direito real, o exerce utilizando a coisa sem ser preciso qualquer intermediário (GOMES, 1999, p. 15).

Embora a alternativa proposta por Orlando Gomes seja viável, ela parece carecer de maiores explicações técnicas, sendo necessária uma maior investigação sobre o assunto.

Pode-se, sem embargo, localizar na doutrina - merecendo referência, entre outros, a obra de Ricardo Aronne -, uma teoria que não busca separar em categorias estanques os planos obrigacional e real sob pena de afastar o Direito Civil "[...] da incidência da normatividade constitucional das relações interprivadas [...]" (ARONNE, 1999, p. 30), mas sim conciliar a teoria realista e a teoria personalista em um só conceito, o qual apresenta-se como uma melhor solução doutrinária para a consubstanciação dos direitos reais, em especial o direito de propriedade. Ao contrário do que possa parecer, esta teoria não soma as carências das duas teorias que busca agregar, mas faz com que uma complemente a outra.

Para Aronne (1999, p. 31),

[...] o Direito Civil [...] se comunica como um todo e com o todo no qual se insere, sendo inadmissível os direitos reais serem vislumbrados como espécie atomizada e apartada. Trata-se de uma categoria de direitos subjetivos plurais ou individuais, que se inserem e transitam no todo do sistema.

Nesse sentido, 
[...] o direito de propriedade se vislumbra a partir do proprietário em relação aos demais indivíduos, já o domínio se vislumbra de modo diverso, ou seja, do indivíduo em reação ao bem. Na concepção clássica, o domínio seria, então o conjunto das relações entre o indivíduo e a coisa, expresso pelo "jus fruendi, utendi e disponendi" (ARONNE, 1999, p. 5).

Aronne inova ao dissociar algo que para muitos é tratado erroneamente como sinônimo; ele separa o domínio da propriedade, justificando que "[...] conforme se observava em Carbonnier, a propriedade contemporânea possui elementos de ordem real e pessoal a conviver em um mesmo instituto." (ARONNE, 1999, p. 34).

Como visto, Aronne não separa os direitos reais dos obrigacionais de modo radical e, ainda, divide o direito subjetivo propriedade em dois elementos, um interno (o domínio - relação direita do sujeito com a coisa) e outro externo (consistente na relação entre o proprietário e os demais membros da sociedade, ou seja), valendo-se da teoria realista para explicar aquele e da teoria personalista para explicar este.

Ao fazer esse arremate teórico na definição de direitos reais, em especial no direito de propriedade, e ao não desvinculá-lo dos direitos obrigacionais, a proposta explicitada pelo referido autor se insere na seara da repersonalização dos direitos reais e da "despatrimonialização" do direito das coisas, ou seja, para o "[...] deslocamento de enfoque dos códigos do patrimônio para a pessoa humana" (ARONNE, 1999, p. 41). Ele permitiu que a "via de mão dupla" das obrigações interpelasse o direito das coisas através de seu elemento externo, que se consubstancia tanto no direito do proprietário de opor a sua propriedade erga omnes quanto no dever de respeitar as exigências da função social da propriedade e de tudo aquilo que tenda ao seu cumprimento.

A função social da propriedade vincula-se de maneira estreita com o tema aqui tratado, uma vez que é elemento do direito de propriedade, estando disciplinada constitucionalmente no artigo $5^{\circ}$, inciso XXIII; e nos artigos 182 e 186. Entretanto, devido à abrangência desse tema, limitamo-nos a dizer que a função social impõe à propriedade a realização de contributos que podem se dirigir à coletividade em sentido amplo, a terceiros 
determinados ou aos próprios proprietários e/ou possuidores, deixando de ser um direito absoluto e abstrato para concentrar uma série de deveres. Nesse sentido, não seria exagero dizer que, segundo a atual ordem constitucional, a propriedade obriga.

\subsection{Posse}

Para Savigny, a posse é subjetiva, sendo a conjugação do corpus (coisa) com o animus domini (ânimo de ser dono, agir como se dono fosse). Para Ihering, a posse é objetiva, consistindo apenas no corpus (coisa); tendo sido esta a teoria, segundo a doutrina pátria, que o direito brasileiro acabou por adotar predominantemente. Para ele, a posse seria a guarda avançada da propriedade:

Posse é o poder de fato, e a propriedade o poder de direito, sobre a cousa. Ambas podem encontrar-se reunidas no proprietário, como também estar separadas [...]: ou o proprietário transfere a outro a posse [possessio justa], reservando para si a propriedade, ou a posse da cousa lhe é tirada contra a sua vontade [possessio injusta]. [...] A importância prática que esse direito representa para ele, é evidente. A utilização econômica da propriedade tem como condição a posse. (IHERING, 1957, p. 9).

Em suas conclusões, Ihering (1957. p. 13) apresenta que "[...] a noção de propriedade implica necessariamente no direito do proprietário à posse".

Quanto à natureza da posse, se ela é um direito ou um fato, verifica-se que o assunto ainda é controverso. Segundo Ihering (1957, p. 52), ela é um direito, pois, segundo ele, “[...] os direitos são os interesses juridicamente protegidos." Essa, entretanto, é a doutrina minoritária. A doutrina majoritária entende que a posse é um fato, senão vejamos:

Parece-nos que a posse não é direito, pois produz seus efeitos sem que se tenha de indagar do título ou da existência do direito do possuidor. "A posse, como a vida, é um fato, sendo tão somente jurídico o meio utilizado pela lei para proteger ou destruir este fato"(Marcel Planiol). (WALD, 2002, p. 49). 
Embora seja esse o entendimento prevalente acerca da posse, não se pode olvidar que não é apenas porque algo (e.g. vida) é um fato que deixa de ser um direito. Por este motivo, entende-se ser aplicável este mesmo raciocínio à posse, cuja natureza de direito não resta debelada tão-somente pela sua natureza fática.

Não obstante a magnificência das lições de Ihering, Antonio Hernandez Gil, em 1967, aponta para a existência da função social da posse, afirmando que "[...] la regulación posesoria está muy ligada a la realidad social em un grado superior a la de los demás derechos [...], la posesión es la instituición jurídica de mayor densidad social." (GIL, 1980, p. 52). Ademais, protesta o autor espanhol acerca das teorias possessórias até então desenvolvidas, nomeadamente as de Savigny e de Ihering, afirmando que "[...] las teorías revales adolecen de la misma quiebra: la necesidad de la propriedad para entender la posesión cuando esta es uma institución socialmente primaria, antepuesta." (GIL, 1980, p. 72).

Destarte, verifica-se que a teoria autônoma da posse é mais satisfatória do que aquelas até então desenvolvidas, uma vez que a posse, segundo Hernandez Gil, consubstancia-se tanto em um fato quanto em um direito autônomo, não inerente à propriedade.

Embora quase a totalidade da doutrina pátria defenda que o sistema possessório brasileiro guarda correspondência com a teoria objetiva delineada por Ihering, verifica-se que este posicionamento é insatisfatório, uma vez que, ao aceitar a posse como guarda avançada da propriedade, vincula o direito de posse ao direito de propriedade de forma que a posse não possa ser pensada senão sob a ingerência do direito de propriedade, direta ou indiretamente. A consequência negativa deste posicionamento é patente: mitiga-se a autonomia da posse em relação à propriedade, impossibilitando que a função social possa ser cumprida única e exclusivamente pela posse.

Além disso, essa divisão tão tênue entre fato e direito enseja uma série de celeumas doutrinários, especialmente após a edição da Súmula n. 
84 do Superior Tribunal Eleitoral (STJ) ${ }^{3}$, quando a posse começou a ter consolidada jurisprudencialmente sua autonomia em relação à propriedade ao ser elemento de legitimidade pública quando a relação de base se pautar em compromisso de compra e venda (direito obrigacional) destituído de registro em cartório. Essa autonomia, fonte de uma série de controvérsias, será analisada de melhor maneira mais à frente, mas, de antemão, adianta-se que ela somente é tecnicamente possível se separação entre os planos real e obrigacional for tida por relativa.

\section{A Relatividade da Separação entre os Planos Real e Obriga- cional}

A obrigação como processo, para Clóvis do Couto e Silva, salienta os "[...] aspectos dinâmicos que o conceito de dever revela, examinando-se a relação obrigacional como algo que se encadeia e se desdobra em direção ao adimplemento." (SILVA, 2008, p. 18).

Assim sendo, a obrigação não se resume no clássico recorte entre parte devedora e parte credora (como exposto pelos conceitos clássicos), perfaz-se em um vínculo complexo, no qual ambas as partes são cocredoras e codevedoras, ou seja, tem tanto direitos quanto deveres recíprocos, os quais se manifestam na relação obrigacional visando ao adimplemento, que, teleologicamente, é o fím último do contrato (SILVA, 2008, p. 22).

A obrigação como processo, entretanto, não se consubstancia tão-somente nesse aspecto. Através dela, segundo Clóvis do Couto e Silva, Larenz percebeu que as regras que coordenam a obrigação se dirigem à prestação, produzindo consequências e desdobramentos da relação contratual com o fim de alcançar seu objetivo último: o adimplemento.

Nesse sentido, buscando melhor estruturar a sua tese, Clóvis do Couto e Silva foi em busca das bases do sistema brasileiro de transmissão

\footnotetext{
3 STJ Súmula n. 84: Embargos de Terceiro - Alegação de Posse - Compromisso de Compra e Venda de Imóvel - Registro. É admissível a oposição de embargos de terceiro fundados em alegação de posse advinda de compromisso de compra e venda de imóvel, ainda que desprovido do registro.
} 
de propriedade, investigando, para tanto, os modelos francês e alemão, investigação esta que será aqui brevemente reproduzida.

\subsection{O Sistema Francês}

O sistema francês clássico de transmissão de propriedade surgiu com o Código Napoleônico (1804) para consubstanciar todas as vitórias burguesas provenientes da revolução de 1789. Uma delas, senão a principal, consistiu na possibilidade de todos poderem exercer a "liberdade" de forma plena, sendo-lhes assegurado o direito, em tese, de adquirir qualquer propriedade (SILVA, 2008, p. 49).

Dessa forma, o contrato servia diretamente à aquisição da propriedade e, consequentemente, à manifestação da liberdade dos particulares, sendo ele, por si só, suficiente à aquisição de um direito real. Ou seja, segundo André Gondinho (2001), no direito francês, o contrato é mero instrumento para se chegar à propriedade, manifestando plena autonomia das partes e possibilitando a circulação de riquezas entre todos (ao menos no plano teórico-legal).

\subsection{O Sistema Alemão}

A lógica do direito alemão é diversa da do francês. Formulado em um momento histórico diferente do Código Napoleônico, o BGB, que foi promulgado em 1896, separou o instituto do contrato do negócio jurídico apto a transmitir a propriedade.

O BGB trouxe, além disso, a disciplina de cada um dos contratos possíveis até então, criando a figura dos contratos típicos, bem como a demarcação de que o contrato não transferiria a propriedade, sendo necessário o registro deste para que, só então, os efeitos dos direitos reais se processassem sobre as partes contratantes, efetuando efetivamente a transferência de propriedade. Isso ocorre porque o BGB tem uma preocupação técnica muito maior do que a do Código Napoleônico, decorrente do avanço doutrinário sobre o tema. 
Essa transferência no sistema alemão perfar-se-ia, segundo Clóvis do Couto e Silva (2008), em três atos: 1) relação obrigacional originária; 2) acordo de transmissão; 3) transmissão do bem através do efetivo registro.

Em suma, para o autor, o BGB tratou de separar de forma absoluta o plano obrigacional do real, guardando, ainda, consigo, à semelhança do sistema francês, a teoria da abstratividade, segundo a qual a propriedade independe de quaisquer ações afirmativas, sendo um direito absoluto.

\subsection{O Sistema Brasileiro}

Tradicionalmente, como se viu, a teoria alemã separava os direitos obrigacionais dos reais pelo seu aspecto interno, atinente aos efeitos, que seriam relativos naqueles e absolutos nesses. A separação dos planos, entretanto, não é satisfatória, já que “[...] não haverá, com efeito, absoluta unidade lógica de critério na classificação [...]”, como apregoa o mestre português Antunes Varela (1997, p. 169).

Opinião recorrente, porém não tecnicamente correta, é a de que o sistema de transmissão brasileiro é igual ao alemão. Venosa, por exemplo, afirma que “[...] o sistema alemão foi adotado em nossa lei de 1916 e mantido no atual estatuto." (VENOSA, 2004, p. 377).

Tamanha rigidez na separação dos planos obrigacional e real não resistiu ao avanço social, sucumbindo pela ineficiência deste sistema, que no afã de garantir a segurança jurídica preteriu outros direitos, como a liberdade material ${ }^{4}$ dos contratantes e, por que não, a própria justiça ao sobrevalorizar dadas formalidades em detrimento da realidade transmissiva informal.

O sistema brasileiro adotou, diferentemente do alemão, segundo Clóvis do Couto e Silva (2008), em seu artigo 859, CC/1916, a causali-

4 Sobre essa liberdade material, já escrevemos que "[...] o contrato, como instrumento de satisfação de necessidades, pode ser visto, também, como um instrumento de livre desenvolvimento da personalidade. Mas essa afirmação deve ser compreendida não, pura e simplesmente, como exercício de autonomia formal: trata-se de ferramenta útil à realização de aspirações existenciais, que se expressam em termos de liberdade positiva, e que somente se mostram viáveis mediante a existência de liberdade como efetividade." (PIANOVSKI RUZYK, 2011. p. 274). 
dade e não a abstratividade. Nessa, eventual nulidade contratual ensejaria tão-somente outra pretensão obrigacional, mas nunca o desfazimento do vínculo de direito real, já que os planos são distintos e ininterpeláveis ${ }^{5}$. Em contrapartida, na causalidade, se o contrato é reputado por nulo, anula-se, consequentemente, o registro, voltando-se ao status quo ante ou, se não for possível, indeniza-se as partes com o equivalente (art. 182, CC).

Destarte, Clóvis do Couto e Silva constatou que o conceito de obrigação como processo somente é aplicável aos sistemas que adotam o sistema finalístico, não sendo aplicável nem aos sistemas que separam de forma absoluta os planos real e obrigacional e nem aos sistemas em que o próprio contrato transmite a propriedade, sendo, nestes casos, mais difícil considerar o desenvolvimento do dever como um processo.

É nesse contexto que o referido autor evidencia a separação relativa dos planos no sistema jurídico brasileiro, tornando possível considerar a obrigação como um processo, que tem significado jurídico específico. Assim, teria o negócio jurídico obrigacional dupla eficácia, uma no plano real e outra o obrigacional, inexistindo no Brasil o chamado acordo de transmissão do sistema alemão, o qual estaria incorporado no próprio negócio jurídico que o consubstancia.

Rodrigo Xavier Leonardo (LEONARDO, 2005) traz a lume do atual Código Civil as conclusões do mestre gaúcho, verificando os casos em que a separação relativa dos planos se evidencia legislativamente, in verbis:

Art. 307. Só terá eficácia o pagamento que importar transmissão da propriedade, quando feito por quem possa alienar o objeto em que ele consistiu.

Parágrafo único. Se se der em pagamento coisa fungível, não se poderá mais reclamar do credor que, de boa-fé, a recebeu e consumiu, ainda que o solvente não tivesse o direito de aliená-la.

Art. 358. Se for título de crédito a coisa dada em pagamento, $a$ transferência importará em cessão.

5 Clóvis do Couto e Silva admitiu, entretanto, que a jurisprudência alemã mais recente estaria admitindo a possibilidade de contágio entre os planos obrigacional e real, mas que o tema era grandemente controvertido e combatido. 
Art. 880. Fica isento de restituir pagamento indevido aquele que, recebendo-o como parte de dívida verdadeira, inutilizou o título, deixou prescrever a pretensão ou abriu mão das garantias que asseguravam seu direito; mas aquele que pagou dispõe de ação regressiva contra o verdadeiro devedor e seu fiador.

Art. 884. Aquele que, sem justa causa, se enriquecer à custa de outrem, será obrigado a restituir o indevidamente auferido, feita a atualização dos valores monetários. (grifos nossos).

Verifica-se nos artigos transcritos que a eficácia no plano real conserva pressupostos de natureza obrigacional, o que comprova a tese da divisão relativa dos planos.

\subsection{Histórico do Sistema Brasileiro}

O sistema brasileiro de transmissão de propriedade descrito no ponto anterior tem sua razão de ser. Ele não é fruto da pura técnica pandectista, bem como não é uma mera cópia do sistema alemão; ele é fruto da evolução histórica da propriedade em nosso país. Destarte, visando compreender essa evolução - e tendo em mente que essa investigação não faz parte do objetivo central do presente artigo, embora seja a ele essencial -, far-se-á um brevíssimo resgate histórico da propriedade brasileira, buscando-se justificar a adoção da divisão relativa dos planos obrigacional e real em nosso país, bem como analisar a influência dessa opção sobre as relações jurídicas, as quais se tornaram muito mais complexas, não mais se consubstanciando nos parâmetros típicos delineados pelo Código Civil.

Segundo Laura Beck Varela, o regime de distribuição de terras adotado pela Coroa Portuguesa no Brasil colonial foi o das sesmarias. Esse regime consiste numa permissão dada pela Coroa aos donatários, que teriam de explorar as terras, embora tenha sido empregado com extremo sucesso na Europa feudal, em 1375, por D. Fernando I, quando as propriedades estavam improdutivas em virtude da peste negra, que reduziu consideravelmente a mão de obra europeia, aqui no Brasil esse regime foi um desastre, uma vez que o interesse de Portugal sobre as terras brasileiras era inicialmente o de manutenção da posse, passando a uma colonização de ocupação, e não de povoamento, como nas colônias do norte. 
Consolidada a propriedade em nome de Portugal, o Brasil passou a sofrer uma colonização de exploração, a qual tinha como seus pilares a monocultura (cana-de-açúcar), o latifúndio e a mão de obra escrava (FURTADO, 2007).

Com a economia edificada sobre esse tripé, Laura Beck Varela coloca que, somados, tais fatores construíram a ideia do que é ser pessoa, do que é coisa, e dos papéis reservados às pessoas e às coisas, emanando para o direito tais linhas divisórias, as quais demarcaram o âmbito dos homens e o das coisas.

Sobreveio então, em 1850, a Lei de Terras (Decreto n. 601), que possibilitou a compra e venda das terras devolutas no país. Com isso, a terra deixou de ser apenas um meio de produção e passou a ter valor de troca, ingressando no sistema jurídico brasileiro o conceito moderno de propriedade, no qual há a
[...] absolutização da propriedade [como] um processo de ruptura em relação a uma estrutura hierarquicamente organizada de deve- res, obrigações, honra e lealdade [...] a nível legislativo e [...] dou- trinário [...] de uma nova realidade política e econômica, que não mais se coaduna com a propriedade condicionada prevista no orde- namento de então (BECK VARELA, 2005, p. 122).

Há, portanto, na propriedade moderna, o afastamento da efetividade (posse) em prol da abstratividade (propriedade absoluta).

Não tardou para que o sistema hipotecário permitisse a mercantilização da terra e um intenso processo de grilagem envolvendo os registros e a transcrição dos imóveis. Frente à desqualificação da posse pelo artigo 11 da Lei de Terras $^{6}$, tornou-se necessário o título para se adquirir a pro-

\footnotetext{
6 Art. 11. Os posseiros serão obrigados a tirar títulos dos terrenos que lhes ficarem pertencendo por effeito desta Lei, e sem elles não poderão hypothecar os mesmo terrenos, nem aliena-los por qualquer modo. Esses títulos serão passados pelas Repartições Provinciaes que o Governo designar, pagando-se cinco mil réis de direitos de Chancellaria pelo terreno que não exceder de hum quadrado de quinhentas braças por lado, e outrotanto por cada igual quadrado que demais contiver a posse; e alêm disso quatro mil réis de feitio, sem mais emolumentos ou sello (BECK VARELA, 2005, p. 171).
} 
priedade. Isso revelou “[...] a caótica organização fundiária do país, com o atraso na agricultura e na economia em geral, dando ênfase à necessidade de proteção ao crédito [para a hipoteca]." (BECK VARELA, 2005, p. 172).

Nesse contexto turvo, foi elaborada a Lei n. 1.237, de 1864, a qual procurou romper com o regime das hipotecas ocultas e instituiu o registro para a transcrição dos títulos de transmissão de imóveis intervivos e de constituição de ônus reais. "Trata-se de embrião do atual sistema, que consagraria a relativa separação de planos entre o direito real e o direito obrigacional." (BECK VARELA, 2005, p. 179).

Logo, frente à dimensão do país, tornou-se inviável tanto a implantação do sistema francês quanto do sistema alemão, como constatado por Laura Beck Varela, sendo necessária a separação relativa dos planos real e obrigacional.

\subsection{Conclusões Parciais Sobre o Sistema Brasileiro}

Relevante foi o delineamento feito por Clóvis do Couto e Silva quanto à divisão dos planos real e obrigacional, uma vez que permitiu compreender a existência de um meio termo entre o sistema francês de transmissão de propriedade e o sistema alemão.

Isso, aliado à concepção mista e repersonalizadora de propriedade antes citada, e à ideia de posse como fato/direito autônomo em relação à propriedade, tal como proposta por Hernadez Gil, permitiu a crescente autonomização da "[...] posse tendente ao cumprimento da função social [...]" em relação à propriedade (SÚMULA, n. 84, STJ).

Nesse âmago, emerge a relevância das ponderações levadas a efeito por Marcelo Domanski (1998), ao refletir sobre a busca de efetivação tanto da segurança jurídica quanto da função social da posse e da propriedade, no que tange à tutela da posse do promitente comprador, antes negada pelo $\mathrm{STF}^{7}$, mas que hodiernamente encontra respaldo jurisprudencial no STJ, consoante se depreende da análise da Súmula n. 84.

7 Súmula n. 621, STF: não enseja embargos de terceiro à penhora a promessa de compra e venda não inscrita no registro de imóveis. (17/10/1984). 


\section{Análise da Súmula n. 84 DO STJ}

Conceber a Obrigação como Processo não significa tão-somente constatar a coexistência de direitos e deveres recíprocos entre as partes, mas tomar consciência de que os planos real e obrigacional podem não ter no direito uma divisão rígida e intransponível.

Frente a tal relativização de planos, aliada à concepção mista de direitos reais, a qual admite a repersonalização deste ramo do Direito Civil, e à tomada de consciência da posse como fato/direito dotado de função social, verifica-se a crescente autonomia da posse em relação à propriedade, bem como a vinculação do direito obrigacional com esta, criando-se uma complexa gama de possibilidades de transmissão da propriedade e exercício de pertencimento, a qual nem sempre se perfaz de maneira uniforme, mas que, não obstante, devem ter sua eficácia reconhecida pela ordem jurídica.

É possível verificar que os bens, cada vez com mais frequência, são transmitidos por contratos atípicos, compostos por diferentes tipos de contrato, e que culminam em algo sui generis, que nem sempre tem seus efeitos previstos legalmente, devendo, por isso, ser circunscritos pelos princípios contratuais e pelas cláusulas gerais da boa-fé objetiva e da função social do contrato ${ }^{8}$.

Foi nesse sentido que o Superior Tribunal de Justiça publicou a Súmula n. 84:

Embargos de Terceiro - Alegação de Posse - Compromisso de Compra e Venda de Imóvel - Registro

É admissível a oposição de embargos de terceiro fundados em alegação de posse advinda de compromisso de compra e venda de imóvel, ainda que desprovido do registro.

8 Frente à extensão deste tema, que não é objeto do presente artigo, pede-se a condolência do leitor para permitir remeter-lho ao artigo de Martins-Costa. 
Primeiramente, essa súmula admitiu a relativização dos planos obrigacional e real, algo que embora já tivesse sido dito doutrinariamente jamais havia tido tão ampla repercussão jurisprudencial.

Além disso, esta súmula ampliou a segurança jurídica material ao permitir que o mero possuidor fosse beneficiado em detrimento do proprietário que não tendia ao cumprimento da função social da propriedade do art. 186, CF. Diz-se material porque a segurança jurídica aqui tutelada não se encerra na afirmação do direito posto, mas na afirmação de uma situação fática consolidada e amparada pela boa-fé e pela posse pública.

Nesse ponto, Marcelo Domanski revelou em sua tese especial preocupação com as fraudes que pudessem emergir dessa autonomização da posse em relação à propriedade, senão vejamos:

Várias são as hipóteses que poderiam ser analisadas para se aferir a configuração de fraude no âmbito do compromisso de compra e venda [...], a saber: a) o imóvel é compromissado à venda e quitado depois da propositura de ação civil, cuja procedência do pedido é causa da insolvência do promitente vendedor [...]; b) o imóvel é compromissado à vende depois de caracterizado o estado de insolvência [...]; c) o compromisso de compra e venda é celebrado e quitado em data anterior à da caracterização da insolvência [...]; d) o compromisso de compra e venda é celebrado em data anterior à da insolvência [...], mas quitado e registrado somente depois da insolvência (DOMANSKI, 1998. p. 180).

Nesse sentido, para que se possa afastar a posse da fraude e, com isso, conferir-lhe autonomia para que concretize direitos fundamentais como o de moradia, deve-se analisar quando do acolhimento de embargos de terceiro que se fundam em compromisso de compra e venda destituído de registro em cartório: a) o termo inicial da posse pública tendente ao cumprimento da função social da propriedade do promitente comprador; b) a data da celebração do compromisso; c) a data da quitação.

Por fim, verifica-se que essa súmula deu à posse pública tendente ao cumprimento da função social a possibilidade de substituir o registro do compromisso de compra e veda, conferindo, com isso, efetividade ju- 
rídica ao "[...] compromisso de compra e venda sem registro em cartório [...]" (DOMANSKI, 1998. p. 64), na medida em que este poderia criar obrigações e conferir ao promitente comprador forte oponibilidade em relação a terceiros e ao próprio vendedor através da possibilidade de propositura de embargos de terceiro.

\section{0 "Contrato de Gaveta" e o Sistema Financeiro da Habitação}

Concebendo a relação obrigacional como um processo e a posse como direito autônomo, desmistifica-se a aparente estabilidade na qual a obrigação se funda teoricamente e, a partir daí, ingressa-se no complexo de relações econômicas desenvolvidas pelo mercado, complexo este que não é regular e não se funda sobre os aspectos típicos do direito contratual, mas sobre diferentes combinações e possibilidades contratuais que visam alcançar o objetivo desejado. Essas combinações nem sempre se encontram adequadamente tuteladas pelo direito, como é o caso do contrato de gaveta.

Devido ao formalismo inerente à transmissão de direitos reais, em especial a propriedade, e à existência no Brasil da necessidade de documentação em dois cartórios (Cartório de Registro de Imóveis e Tabelionato de Notas), além das garantias exigidas por quem financia os imóveis, faz com que no mercado imobiliário os imóveis econômicos, super econômicos e rústicos sejam transferidos à míngua das formalidades exigidas pela lei, sendo, segundo Eros e Noemia Moura Cordeiro (2008, p. 99-100):

[...] um dos grandes desafios do Direito contemporâneo [...] concretizar mecanismos de acesso a bens essenciais [...]. Dentre tais bens "vitais" está a moradia, assegurada em nosso ordenamento jurídico como direito social fundamental

Os autores supracitados destacam que o aumento das aquisições imobiliárias cresceu junto com os requisitos exigidos pelo mercado habitacional para a celebração de contratos de longo prazo, os quais envolvem pessoas que devem se enquadrar em parâmetros rígidos, os quais são exi- 
gidos pelas financiadoras para que tenham maior garantia em um negócio que pode se protrair por até 30 anos.

Justamente por não se adequar aos requisitos exigidos pelos financiamentos, na prática realiza-se o chamado contrato de gaveta, ou seja, um contrato de compromisso de compra e venda sem registro em cartório cumulado com uma procuração destinada à transferência futura da propriedade, comumente realizado entre aqueles não atendem aos requisitos mínimos exigidos para adquirir formalmente um imóvel - mas que têm capacidade fática para tanto - e aqueles que conseguiram o financiamento junto ao banco.

É nesse escopo de crescente mutação que surge a Coligação de Contratos, também conhecida como Redes Contratuais. Varela (1997, p. 284) coloca que

[...] por um nexo funcional que influi na respectiva disciplina, já se não trata de um nexo exterior ou acidental, mas de um vínculo substancial que pode alterar o regime normal de um dos contratos ou de ambos eles, por virtude da relação de interdependência que eventualmente se crie entre eles.

Nesses casos, enquanto um contrato é realizado entre a financiadora e o comprador que atende aos requisitos exigidos pelo mercado habitacional, outro contrato (o contrato de gaveta) é feito, paralela e posteriormente àquele, entre o outrora comprador, agora promitente vendedor, e aquele que de fato pagará as prestações do imóvel, o agora promitente comprador. No caso, este negocia o valor já pago por aquele e assume as parcelas vindouras. Ao final do primeiro contrato, que foi adimplido por um terceiro, estranho à relação jurídica originária, transmitir-se-ia a propriedade ao primeiro comprador; entretanto, frente ao contrato de gaveta, a lógica faz com que o imóvel deva ser transmitido para quem de fato adimpliu o contrato, e não para quem realizou o financiamento junto ao banco.

Cumpre ressaltar que não se trata de cessão contratual, já que o contrato primário resta incólume. Há, portanto, uma rede contratual. Além disso, impende ressaltar que não se trata de um instrumento contrário à 
lei, mas de um contrato atípico, que tem respaldo no artigo 425, CC/2002, e, por isso, deve observar as normas gerais fixadas pelo Código Civil.

Segundo Eros e Noemia Cordeiro (2008, p. 109), “[...] os contratos de gaveta [...] são produtos da exclusão do sistema jurídico e da própria racionalidade do mercado habitacional, que priorizam o aspecto financeiro."

Não se pode olvidar que o mercado habitacional rege-se pelo lucro inerente ao risco de sua atividade e, para tal, deve guardar garantias que tornem o investimento economicamente viável, mas o que não se pode fazer é encobrir a eficácia jurídica desse contrato atípico, que contornou dificuldades materiais para se estabelecer juridicamente e, por ter fundamental papel na concretização da dignidade da pessoa humana por meio da moradia própria, não pode ter seus efeitos suprimidos por mero formalismo jurídico.

Vejamos a jurisprudência sobre o assunto:

Revisão Contratual. Sistema Financeiro de Habitação. Contrato de Gaveta. Preliminar de Carência de Ação Rechaçada. Aplicação do CDC. Admissibilidade. "Consectariamente, o cessionário de imóvel financiado pelo SFH é parte legítima para discutir e demandar em juízo questões pertinentes às obrigações assumidas e aos direitos adquiridos através dos cognominados "contratos de gaveta", porquanto com o advento da Lei n. ${ }^{\circ} 10.150 / 2000$, o mesmo teve reconhecido o direito à sub-rogação dos direitos e obrigações do contrato primitivo". (REsp 857548/SC n. 2006/0119305-5, rel. Min. Luiz Fux, Primeira Turma, j. 4-10-2007, DJ de 8.11.2007, p. 178).

Com isso, verifica-se que o contrato de gaveta constitui instrumento que pode resultar na transmissão de propriedade, concretizando o acesso à moradia e vinculando seus efeitos ao agente financeiro, que não teve quaisquer prejuízos nesse negócio jurídico. Se o contrato de gaveta guardou boa-fé objetiva (na medida em que atendeu ao que a outra parte esperava - o adimplemento) e cumpriu a função social do contrato (na medida em que atendeu tanto sua função interna, qual seja a da justiça contratual através do adimplemento proporcional de ambas as partes, quanto sua função externa, qual seja a de atender, segundo o artigo 2.035, Código 
Civil, à coletividade através da concretização do direito à moradia) não há porque negar-lhe eficácia transmissiva.

\section{Conclusões}

A potencialização das possibilidades de transmissão de bens nem sempre se perfaz de maneira simples. Muito pelo contrário, a complexidade econômica e a questão social que circundam essas possibilidades não se pautam pela tipicidade contratual, mas sobre combinações e possibilidades contratuais que visam atender às necessidades do negócio in concreto, conduzindo ao adimplemento. Como essas combinações nem sempre são tuteladas satisfatoriamente pelo direito (exemplo: compromisso de compra e venda sem registro em cartório, contrato de gaveta etc.), necessária se faz a releitura de conceitos e estruturas tradicionais, a fim de concretizar os preceitos constitucionais, em linha coma dimensão funcional do Direito Civil, centrada, sobretudo, na promoção de liberdade(s) (inclusive de caráter material) das pessoas.

Nesse sentido, após os caminhos percorridos no presente artigo, chegamos às seguintes conclusões:

a) A obrigação não compreende uma relação jurídica estática, dotada de um polo ativo (credor) e outro passivo (devedor), mas sim consubstancia-se em um complexo de direitos e deveres recíprocos, orientados ao adimplemento e tendentes a cumprir os mandamentos da ordem constitucional.

b) Não existe uma divisão estanque entre os planos real e obrigacional, a qual pode se revelar uma distinção artificial; tal divisão pode, inclusive, impedir a realização material de diversos direitos, inclusive alguns assegurados constitucionalmente, como a moradia e um patrimônio mínimo personalíssimo.

c) A partir da última conclusão, tem-se, também, que uma teoria sobre os direitos reais que integre em sua estrutura tanto a dimensão real como a relacional (pertinente à relação com o sujeito passivo universal) é mais adequada, estruturando a proprie- 
dade em dois elementos constituintes: um de natureza interna - correspondente aos poderes inerentes àquilo que comumente se chama domínio - e outro de natureza externa - correspondente ao plexo de direitos e deveres envolvendo o titular do direito e terceiros (sujeito passivo universal).

d) Decorrente das outras três conclusões, verifica-se ser necessário tratar a posse como fato/direito autônomo em relação ao direito de propriedade, podendo ela se sobrepor ao direito de propriedade de caráter abstrato, como no caso do compromisso de compra e venda destituído de registro em cartório, no qual a posse autônoma tendente ao cumprimento da função social é hábil a dar a devida publicização desde contrato para conferir ao promitente comprador forte oponibilidade frente ao próprio vendedor e frente a terceiros. A posse, aqui, é a ponte que faz o necessário liame entre a situação obrigacional, que se expressa contratualmente, $o$ exercício do pertencimento, de natureza real;

e) No caso do denominado contrato de gaveta, desde que tenha ele guardado boa-fé objetiva e cumprido a função social do contrato, não há porque negar-lhe eficácia transmissiva, podendo esta ser, também, uma hipótese de concretização do constitucionalmente previsto direito à moradia - e, nessa medida, de incremento de liberdade de natureza material.

\section{Referências}

ARONNE, Ricardo. Propriedade e domínio. Rio de Janeiro: Renovar, 1999.

BECK VARELA, Laura. Das sesmarias à propriedade moderna: um estudo de história do direito brasileiro. Rio de Janeiro: Renovar, 2005.

BRASIL. Lei n. 10.406, de 10 de janeiro de 2002: institui o Código Civil. Disponível em: <http://www.planalto.gov.br/ccivil_03/leis/2002/ L10406.htm>. Acesso em: $1^{\text {o }}$ out. 2011. 
. Superior Tribunal de Justiça. Súmula 84. Disponível em:

$<\mathrm{http} / /$ www.stj.jus.br/SCON/sumulas/doc.jsp?livre=\%40docn\&\&b=SU MU\&p=true \& $\mathrm{t}=\& \mathrm{l}=10 \& \mathrm{i}=388>$. Acesso em: 9 out. 2011.

. Superior Tribunal de Justiça. REsp 857548/SC n. 2006/01193055, rel. Min. Luiz Fux, Primeira Turma, j. 4-10-2007, DJ de 8.11.2007, p. 178.

. Supremo Tribunal Federal. Súmula 621. Disponível em: $<$ http:// www.stf.jus.br/portal/jurisprudencia/listarJurisprudencia.asp?s1=621. NUME. NAO S.FLSV.\&base=baseSumulas $>$. Acesso em: 9 out. 2011.

DIDIER JR., Fredie. A função social da propriedade e a tutela processual da posse. In: RePro, n. 161, julho de 2008. São Paulo: Revista dos Tribunais. 2008.

DOMANSKI, Marcelo. Posse: da Segurança Jurídica à Questão Social. Rio de Janeiro: Renovar, 1998.

FACHIN, Luiz Edson. A função social da posse e a propriedade contemporânea. Porto Alegre: Sergio Antonio Fabris, 1988.

. Teoria Crítica do Direito Civil. Rio de Janeiro: Renovar, 2000.

FURTADO, Celso. Formação econômica do Brasil. 34. ed. São Paulo: Companhia das Letras, 2007.

GIL, Antonio Hernandez. La posesión. Madrid: Civitas, 1980.

GOMES, Orlando. Direitos reais. 19. ed. São Paulo: Editora Forense, 1999.

. Contratos. 26. ed. São Paulo: Editora Forense, 2009.

GONDINHO, André Pinto da Rocha Osorio. Direitos reais e autonomia da vontade. Rio de Janeiro: Renovar, 2001.

LEONARDO, Rodrigo Xavier. A cessão de créditos: reflexões sobre a causalidade na transmissão de bens no direito brasileiro. Revista da Faculdade de Direito da UFPR, v. 42, p. 133-145, 2005.

. Redes contratuais no mercado habitacional. São Paulo:

Revista dos Tribunais, 2003. 
LORENZETTI, Ricardo. Redes Contractuales: conceptualización jurídica, relaciones internas de colaboración, efectos frente a terceros. Revista de Direito do Consumidor, São Paulo: Revista dos Tribunais, n. 8, out./dez. 1998.

IHERING, Rudolf Von. Teoria simplificada da posse. Salvador: Livraria Progresso Editora, 1957.

MARQUES. Cláudia de Lima. Dos contratos no direito do consumidor. 5. ed. São Paulo: Revista dos Tribunais, 2006. MARTINS-COSTA, Judith. Cláusulas gerais no Novo Código Civil. [2010?]. Disponível em: $<$ http://jus2.uol.com.br/doutrina/texto. asp?id=8077>. Acesso em: 11 ago. 2010.

MELLO, Marcos Bernardes de. Teoria do fato jurídico: plano da existência. 15. ed. rev. São Paulo: Saraiva, 2008.

MOURA CORDEIRO, Eros Berlin de; MOURA CORDEIRO, Noemia Paula Fontanela de. Dignidade jurídica dos contratos de gaveta: em busca da concretização do acesso à moradia. In: TEPEDINO, Gustavo; FACHIN, Luiz Edson (Coord.). Diálogos sobre Direito Civil, v. II. Rio de Janeiro: Renovar, 2008.

PIANOVSKI RUZYK, Carlos Eduardo. Institutos fundamentais do direito civil e liberdade(s): repensando a dimensão funcional do Contrato, da Propriedade e da Família. Rio de Janeiro: GZ, 2011.

RODRIGUES, Silvio. Direito civil - parte geral das obrigações. 30. ed. São Paulo: Saraiva, 2002.

SARLET, Ingo Wolfgang. Dimensões da dignidade: ensaio de filosofia do direito e direito constitucional. Porto Alegre: Livraria do Advogado, 2005.

SILVA, Clóvis V. Do Couto e. A Obrigação como processo. São Paulo: FGV, 2008.

TEPEDINO, Gustavo. A responsabilidade civil nos contratos de turismo. In: Temas de direito civil. Rio de Janeiro: Renovar, 2004. 
TEPEDINO, Gustavo; FACHIN, Luiz Edson (coord.). Diálogos sobre direito civil. v. II. Rio de Janeiro: Renovar, 2008.

VARELA, João de Matos Antunes. Das obrigações em geral, v. I. 7. ed. Coimbra: Almedina, 1997.

VENOSA, Silvio de Salvo. Direito civil: direitos reais. 8. ed. São Paulo: Atlas, 2004.

. Direito civil: teoria geral das obrigações e teoria geral dos contratos. 8. ed. São Paulo: Atlas, 2004.

WALD, Arnoldo. Direito das coisas. 11. ed. São Paulo: Saraiva, 2002. 